\title{
Interactions between feed system and process in production of preforms as linked micro parts
}

\author{
Philipp Wilhelmi ${ }^{1,3, *}$, Christine Schattmann ${ }^{4}$, Christian Schenck $^{1,2,3}$ and Bernd Kuhfuss $^{1,2,3}$ \\ ${ }^{1}$ University of Bremen \\ ${ }^{2}$ MAPEX Center for Materials and Processing \\ ${ }^{3}$ bime, Bremen Institute for Mechanical Engineering, Badgasteiner Str. 1, 28359 Bremen, Germany \\ ${ }^{4}$ Bremer Institut für angewandte Strahltechnik GmbH, Klagenfurter Str. 5, 28359 Bremen, Germany
}

\begin{abstract}
This contribution deals with interactions between feed system and process in the production of preforms as linked parts, which is the first step of a multi-stage process chain for cold forming of micro parts. Due to the interconnection of the parts, the feed system is not only used for part transport, but also for the positioning during the generation of the preforms by laser rod melting. Thereby, the influence of the feed system on the production is more significant. Absorbed laser energy melts a wire, so that a melt pool is formed. While the wire is fixed on one side, the other side is fed into the melt pool whose volume increases. The production can be divided in the steps of preheating, active melting, solidification and transportation. The positioning takes place in parallel to the melting. Until now, the increase of the output rate was based especially on the consideration of the melting process and higher feed velocities. In this contribution, the interactions between feed and process are analyzed with the goal of further increasing the output rate. For that reason, the positioning behavior and its influence on the geometry of the produced preforms are analyzed. Finally, a method is presented, which unites the steps of transportation, preheating and melting. It is shown, that by a favorable coordination of the individual process steps, a further increase of the output rate is achievable without significantly worsening part quality.
\end{abstract}

Keywords: Handling, Positioning, Laser micro machining

\section{Introduction}

The technical trend towards increasing functional integration and at the same time more compact products leads to an increasing demand for micro parts. However, technical or economic reasons may complicate the adaption of processes to micro range. To meet the micro specific requirements, not only alternative processes, but also new production methods are necessary. Like stated by Alting in [1] a great variety of possible manufacturing processes for micro production is available. But as the product design may completely change depending on the manufacturing process, it is very important to take these processes into account at an early stage of the product development. The appearing of size effects [2] and the often high sensitivity to mechanical damages complicate handling and thereby make a production at high output rates very difficult [3]. Precise damage-free gripping of micro components as well as overcoming the dominant adhesion forces when releasing is technically challenging $[4,5]$. The single manufacturing processes can only be successfully applied, if they go along with a production concept enabling an economically rentable production. Arentoft introduces a multistage micro bulk forming system based on individual part handling in [6].
The system is specified at a rate of 50 parts per minute. As an alternative approach in order to simplify the handling, the production as linked parts is investigated for micro cold forming [7]. In [8] investigations for the production of bulk formed micro parts as linked parts based on sheet metal with a thickness of 1,2 and $3 \mathrm{~mm}$ are presented. In this case, several forming steps are required to produce billets within the strip material. These billets, which remain interconnected by the strip, serve as basis for the actual forming process. In this work, a process chain is considered, which could be used for example to produce micro valve tappets or camshafts. In a first step preforms are generated within a wire by laser rod melting $[9,10]$, see Fig. 1.

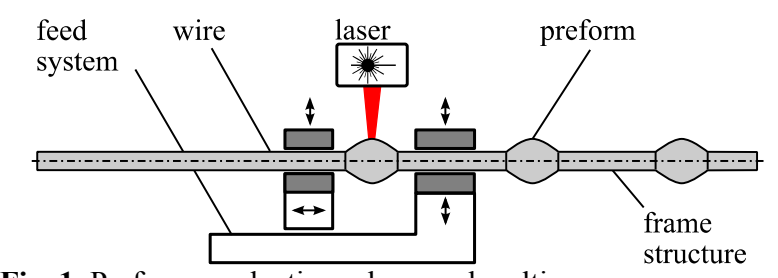

Fig. 1. Preform production - laser rod melting

In a second step, the linked parts can be positioned in a forming tool [11] and the preforms can be cold formed for example by rotary swaging [12, 13], see Fig. 2 .

\footnotetext{
* Corresponding author: wilhelmi@,bime.de
} 


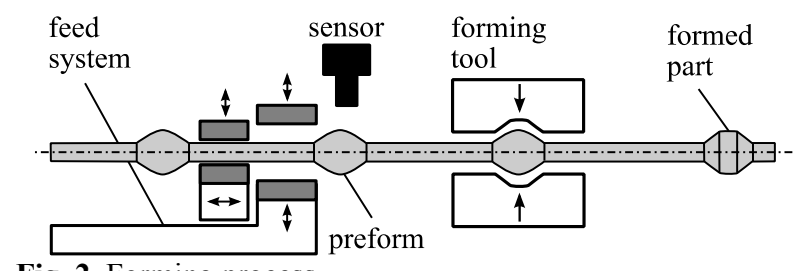

Fig. 2. Forming process

This paper deals with the laser rod melting. The basic principle of the process is analyzed in [9]. In [10] the currently considered process is presented and measures for influencing the part geometry are investigated at a feed velocity of $\mathrm{v}_{\text {feed }}=5.9 \mathrm{~mm} / \mathrm{s}$. In [14] the feed velocity could be raised to $\mathrm{v}_{\text {feed }}=50 \mathrm{~mm} / \mathrm{s}$ and a cycle time according to Table 1 could be reached, by using the new developed feed system, which is also applied for the investigations in the current work.

This contribution addresses the interactions between feed system and process in the production of the linked micro parts. The parts remain interconnected and are fed as a string through all production stages. The feed system is not only used for transportation and positioning between single stages, but also for feeding during processes. It is analyzed, how the feed system behaves, when further reducing cycle times and how this affects the process.

Table 1. Process times for $\mathrm{v}_{\text {feed,max }}=50 \mathrm{~mm} / \mathrm{s}$, $\mathrm{x}_{\text {feed }}=1.7 \mathrm{~mm}$ and $\mathrm{x}_{\text {transport }}=10 \mathrm{~mm} \mathrm{[14]}$

\begin{tabular}{|c|c|}
\hline Process step & time \\
\hline preheating & $7 \mathrm{~ms}$ \\
\hline melting & $34 \mathrm{~ms}$ \\
\hline solidification & $130 \mathrm{~ms}$ \\
\hline transport & $100 \mathrm{~ms}$ \\
\hline \hline cycle time & $271 \mathrm{~ms}$ \\
\hline
\end{tabular}

\section{Methods}

The process of laser rod melting is based on the effect that in micro range surface tension dominates against the gravitational force [9]. Thereby, when melting a wire with absorbed laser energy, the melt pool forms a spherical drop and the resulting preform solidifies connected to the wire. For the rod melting of linked parts the feed system feeds the wire during the melting and consequently has a significant influence on the part geometry. The process is illustrated in Fig. 3 and additionally the single actions are listed in Table 2. The feed system is based on two grippers, where one is mounted on a feed axis (Fig. 3, gripper 1) and the other one is fixed in place (Fig. 3, gripper 2). In the initial position, both grippers are closed. Then the laser is switched on with a constant set power $\mathrm{P}_{\text {laser }}$. The laser beam is focused on the wire between both grippers at an invariant position relative to the feed system. When the wire starts melting, gripper 1 is moved towards gripper 2. Thereby, further wire material is molten and forms an increasing spherical melt pool. Reaching a certain position $\mathrm{x}_{\text {feed, }}$, the feed is stopped, the laser is switched off and the melt solidifies. Afterwards, a return stroke follows: Gripper 1 is opened, the axis moves back and gripper 1 is closed again. Then the forward stroke is performed: Gripper 2 is opened and the generated intermediate form is transported by moving gripper 1 to the initial position again. Finally, gripper 2 is closed and a new cycle can start. Considering the motion of the linked parts, two positioning processes are performed. The positioning during the melting step is named feed in the following. The transport is composed of the return stroke and the forward stroke and also involves the gripping. For the scheme in Fig. 3 the part distance $\mathrm{x}_{\text {transport }}$ is defined by the forward stroke distance $\mathrm{x}_{\text {forward }}$.

$$
\mathrm{X}_{\text {transport }}=\mathrm{X}_{\text {forward }}
$$

The return stroke is defined as the sum of the forward stroke $\mathrm{x}_{\text {forward }}$ and the feed $\mathrm{x}_{\text {feed }}$.

$$
\mathrm{X}_{\text {return }}=\mathrm{x}_{\text {forwrward }}+\mathrm{x}_{\text {feed }}
$$

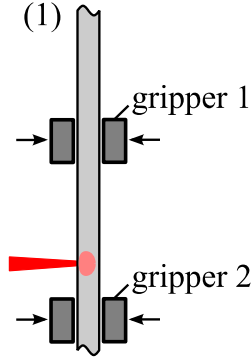

preheating

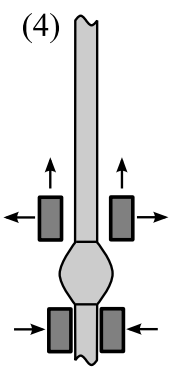

transport

(return stroke)
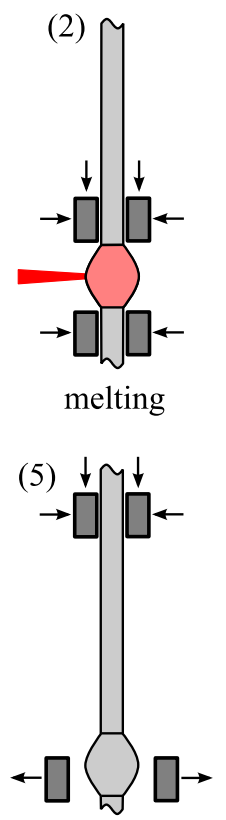

transport

(forward stroke)
Fig. 3. Laser rod melting as linked parts, sequential process

\begin{tabular}{|c|c|c|c|}
\hline process step & single actions & $\begin{array}{c}\text { detailed } \\
\text { time }\end{array}$ & $\begin{array}{l}\text { step } \\
\text { time }\end{array}$ \\
\hline preheating & laser on & - & $t_{\text {preheat }}$ \\
\hline melting & laser on, feed & - & $t_{\text {feed }}$ \\
\hline solidification & laser off, wait & - & $t_{\text {solid }}$ \\
\hline \multirow[t]{6}{*}{ transport } & open gripper 1 & $t_{\text {gripper } 1,0}$ & \multirow[t]{6}{*}{ transport } \\
\hline & return stroke & $t_{\text {return }}$ & \\
\hline & close gripper 1 & $t_{\text {gripper } 1, \mathrm{c}}$ & \\
\hline & open gripper 2 & $t_{\text {gripper2,o }}$ & \\
\hline & forward stroke & $t_{\text {forward }}$ & \\
\hline & close gripper 2 & $t_{\text {gripper2,c }}$ & \\
\hline \multicolumn{3}{|l|}{ total cycle } & $t_{\text {cycle }}$ \\
\hline
\end{tabular}

Table 2. Cycle time in detail 
In order to reduce the cycle time, the scheme from Fig. 3 can be modified by parallelizing the steps of preheating (1) and transport (5), as illustrated in Fig. 4. In this case, a cycle starts with step (5). The preheating and the closing of gripper 2 are initiated during the forward stroke and a direct transition to the feed is performed without stopping the motion. After the time necessary for closing gripper $2 t_{\text {gripper2,c, }}$, the gripper stops the lower part of the wire, which contemporaneously starts to melt. At that time the velocity is reduced from $v_{\text {transport }}$ to $\mathrm{v}_{\text {feed. }}$. When $\mathrm{x}_{\text {feed }}$ is reached, the feed is stopped and the laser is switched off. The solidification and return stroke are equal to Fig. 3. The parallelization leads to a reduction of the times for closing gripper $2 t_{\text {gripper2,c }}$ and the preheat time $t_{\text {preheat. }}$.

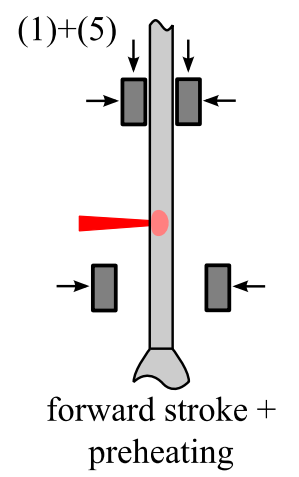

Fig. 4 Parallelization of preheating and transport

For this purpose, an appropriate feed system, which provides adequate acceleration and feed velocity, has been developed. According to the aforementioned principle it is based on two grippers. The feed axis of the moving gripper is driven by a linear direct drive with a direct position sensor. The grippers are actuated pneumatically and their alignment is realized by constructive measures. Segmented prismatic jaws with a center bar enable a self-centering and deformation free gripping. This is especially important to maintain the collinear orientation of the wire ends, when the wire is molten by the laser. To demonstrate the challenges, in Fig. 5 possible process failures that may appear in consequence of an incorrect process coordination are illustrated.

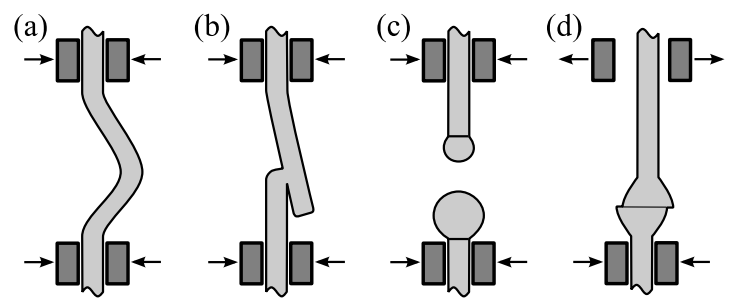

Fig. 5. Process failures

(a) The preheating energy is too low. - The material does not melt and the wire buckles when the feed starts.

(b) The laser power is too low respectively the feed velocity is too high. - The wire is molten, but when the feed starts, the wire ends slide off and no melt drop is formed. (c) The laser power is too high respectively the feed velocity is too low. - The melt drop moves along the wire in both directions and the wire is separated into two parts.

(d) The material is not solidified completely when the gripper opens for transport. - The wire ends misalign or even separate.

The failures (a), (b) and (c) do not allow producing proper preforms at all. Failure (d) however destroys the preform even though it has been generated properly. Considering this, it becomes clear that the feed system has a high impact on the process results as well as the cycle time and that the coordination of the single process steps is very important. Consequently, in this work, the feed system and different kinds of interactions are considered under the aspect of reducing the cycle time, while keeping the part quality.

The experiments are evaluated by reading out the direct position sensor of the feed system and by measuring the produced linked parts with an area scan camera in an external measurement setup, which is shown in Fig. 6. The probes are clamped in a probe holder, which is moved with a feed axis while the camera is fixed in place. This way, a measurement of the entire linked parts is performed.

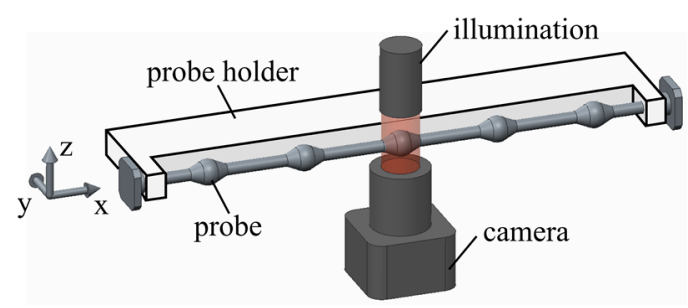

Fig. 6. Probe measurement

As the transmitted light method is applied, the measurement result is a black and white image of the contour. These measurements are two-dimensional, but the samples are not necessarily ideally rotationally symmetric, consequently each sample is measured twice. The first measurement is taken from the perspective, from which the laser beam is aimed on the wire during the experiments. In the second measurement, the sample is rotated around its longitudinal axis (x-axis) by $90^{\circ}$. Fig. 7 shows the measurement of a produced part. Within the image the geometrical parameters, which are determined on basis of an image evaluation, are marked. Those are the part diameter $d_{\text {part }}$, the part length $l_{\text {part }}$, the part volume $V_{\text {part }}$ (Fig. 7a)and the net part volume $V_{\text {part,net }}$ (Fig. 7b).
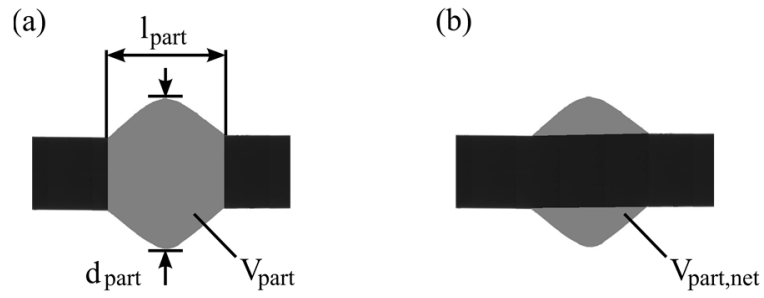

Fig. 7 Measurement of a part - characteristic values 
All the parameters are calculated on basis of the diameter curve of the linked parts. The diameter is determined in discrete steps according the effective resolution of the camera. The part diameters are detected by a peak search. The part length is determined by detecting the diameter transitions between wire and part with the help of a diameter limit. Due to the smooth transition, the determination of the part length is more difficult, which leads to higher standard deviations. As a single characteristic value, the shape number $G$ introduced by Schattmann et al. in [13] is used to compare the parts.

$$
\mathrm{G}=\mathrm{d}_{\text {part }} / \mathrm{l}_{\text {part }}
$$

The part volume $\mathrm{V}_{\text {part }}$ is calculated by numerical integration. At each position $\mathrm{x}$, for the measured diameter $d_{x}$ a cylindrical volume is calculated. These volumes are summated over the part length $1_{\text {part }}$.

$$
\begin{gathered}
\mathrm{V}_{\text {cyl }}=\left(\mathrm{d}_{\mathrm{x}} / 2\right)^{2} \cdot \pi \cdot \operatorname{res}_{\mathrm{x}} \\
\mathrm{V}_{\text {part }}=\Sigma \mathrm{V}_{\text {cyl }}
\end{gathered}
$$

By substracting a cylindrical volume with $1_{\text {part }}$ and wire diameter $d_{\text {wire }}$ from $V_{\text {part }}$ the net part volume $V_{\text {part,net }}$ is calculated.

$$
\mathrm{V}_{\text {part,net }}=\mathrm{V}_{\text {part }}-\left(\mathrm{d}_{\mathrm{wire}} / 2\right)^{2} \cdot \pi \cdot 1_{\text {part }}
$$

The advantage of using $\mathrm{V}_{\text {part,net }}$ is, that it reduces the influence of $l_{\text {part }}$ and thereby is more precise than the part volume. It should ideally be equal to the volume $V_{\text {wire,feed }}$ of the wire fed during the melting process, which can be calculated on base of the feed $x_{\text {feed }}=2 \mathrm{~mm}$ and the wire diameter $\mathrm{d}_{\text {wire }}=360 \mu \mathrm{m}$.

$$
\mathrm{V}_{\text {wire,feed }}=\left(\mathrm{d}_{\mathrm{wire}} / 2\right)^{2} \cdot \pi \cdot \mathrm{x}_{\text {feed }}=0.20 \mathrm{~mm}^{3}
$$

\section{Experiments}

Table 3 summarizes the parameters, which are used in all experiments. The linear motor provides a maximum force of $\mathrm{F}_{\max }=137 \mathrm{~N}$, which results in a maximum acceleration of $\mathrm{a}_{\max } \approx 300 \mathrm{~m} / \mathrm{s}^{2}$ of the feed system. The assumption is made, that a constant feed velocity and thereby a constant fed volume per time increment is favorable, if a constant laser power is applied. For the rod melting experiments presented in this paper a trapezoidal velocity profile is used, the acceleration is set to $\mathrm{a}_{\text {feed }}=100 \mathrm{~m} / \mathrm{s}^{2}$ and the feed velocity is varied up to a maximum of $v_{\text {feed,max }}=90 \mathrm{~mm} / \mathrm{s}$. These parameters result in a maximum acceleration time of $t_{a c c, \max }=0.9 \mathrm{~ms}$. The distance in which the acceleration takes place is $\mathrm{x}_{\mathrm{acc}}=81 \mu \mathrm{m}$. Between a phase of acceleration and deceleration there is a phase of constant feed velocity. Under the assumption of melting $\mathrm{x}_{\text {feed }}=2 \mathrm{~mm}$ of wire as done during the following presented experiments, the time of constant feed is about $20 \mathrm{~ms}$. For lower feed

\begin{tabular}{|c|c|}
\hline parameter & value \\
\hline$a_{\text {feed }}$ & $100 \mathrm{~m} / \mathrm{s}$ \\
\hline$V_{\text {feed }}$ & $30,40, \ldots 90 \mathrm{~mm} / \mathrm{s}$ \\
\hline$P_{\text {Laser }}$ & $100 \ldots 300 \mathrm{~W}$ \\
\hline$E_{\text {preheat }}$ & $\sim 2.1 \mathrm{~J}$ \\
\hline$E_{\text {feed }}$ & $\sim 6.7 \mathrm{~J}$ \\
\hline $\mathrm{x}_{\text {feed }}$ & $2 \mathrm{~mm}$ \\
\hline atransport & $300 \mathrm{~m} / \mathrm{s}$ \\
\hline Vtransport & $600 \mathrm{~mm} / \mathrm{s}$ \\
\hline $\mathrm{X}_{\text {transport }}$ & $10 \mathrm{~mm}$ \\
\hline$d_{\text {wire }}$ & $360 \mu \mathrm{m}$ \\
\hline$V_{\text {part,net, theretical }}$ & $0.2 \mathrm{~mm}^{3}$ \\
\hline material & stainless steel - AISI304 \\
\hline laser & Trumpf TruFiber 300 \\
\hline wave length & $1085 \pm 5 \mathrm{~nm}(\mathrm{cw})$ \\
\hline scanner system & Raylase Turboscan 30 \\
\hline
\end{tabular}
velocities $t_{a c c}$ is even shorter both absolute as well as in relation to the feed time $t_{\text {feed }}$, which is needed to cover the feed distance $\mathrm{x}_{\text {feed }}$.
Table 3. Common experimental parameters

The time composition of the current state of the optimized transport cycle is listed in Table 4. The times given in the table indicate when the next step is initiated by the control unit. These times are based on measurements of the single times, like for example the time for closing gripper 1, but they are not necessarily equal to the measured values. It is already considered that some actions can overlap. For example, gripper 1 does not need to be opened completely to start the return stroke (10 ms instead of $21 \mathrm{~ms})$ or the closing can be initiated before the return stroke is completely finished (14 ms instead of $18 \mathrm{~ms})$. The acceleration is set to $\mathrm{a}_{\text {transport }}=300 \mathrm{~m} / \mathrm{s}^{2}$ and the maximum velocity is set to $\mathrm{v}_{\text {transport }}=0.6 \mathrm{~m} / \mathrm{s}$.

Table 4. Transport time in detail

\begin{tabular}{|l|l|}
\hline open gripper 1 & $10 \mathrm{~ms}$ \\
\hline return stroke & $14 \mathrm{~ms}$ \\
\hline close gripper 1 & $21 \mathrm{~ms}$ \\
\hline open gripper 2 & $17 \mathrm{~ms}$ \\
\hline forward stroke & $18 \mathrm{~ms}$ \\
\hline close gripper 2 & $17 \mathrm{~ms}$ \\
\hline \hline transport time & $97 \mathrm{~ms}$ \\
\hline
\end{tabular}

In the first experiments the behavior of the feed unit is analyzed without involving the process. Like described in the previous section a constant velocity is aspired and consequently a trapezoidal velocity profile with high acceleration is applied. The velocity profile serves as base of the reference input for the controller of the feed unit. The actual position profile respectively velocity profile deviates from this depending on the control parameters and the mechanical properties of the system. This is analyzed by varying the velocity between 
$\mathrm{v}_{\text {feed }}=30 \mathrm{~mm} / \mathrm{s}$ and $\mathrm{v}_{\text {feed }}=90 \mathrm{~mm} / \mathrm{s}$ and comparing the reference values to the measured values from the position sensor. The evaluation is based on the velocity profiles, the position profiles as well as a consideration of specific deviations and the positioning time in dependency of the velocity. For each velocity six repeated measurements are performed. The optical position sensor of the feed unit consists of a Renishaw T1000 encoder and a RGSZ scale with a scale pitch of $20 \mu \mathrm{m}$. The digital interface has a resolution of $0.2 \mu \mathrm{m}$. The feed velocity is gained by numerical differentiation of the position measurement.

For the laser rod melting experiments, a Trumpf TruFiber 300 laser is used. The laser beam is deflected to the machining position with a Raylase Turboscan 30 scanner system. The laser focus position remains fixed at the same point during the process for all experiments. The theoretically induced energy $E_{\text {ind }}$ under the assumption of no losses is kept constant throughout all experiments regardless of $\mathrm{v}_{\text {feed }}$. This is done by adapting the laser power $P_{\text {Laser }}$ and the preheat time $t_{\text {preheat }}$ according to the applied feed velocity and the resulting feed time.

$$
\begin{gathered}
\mathrm{E}_{\text {preheat }}=\mathrm{t}_{\text {preheat }} \cdot \mathrm{P}_{\text {Laser }} \approx 2.1 \mathrm{~J} \\
\mathrm{E}_{\text {feed }}=\mathrm{t}_{\text {feed }} \cdot \mathrm{P}_{\text {Laser }} \approx 6.7 \mathrm{~J} \\
\mathrm{E}_{\text {ind }}=\mathrm{E}_{\text {preheat }}+\mathrm{E}_{\text {feed }} \approx 2.1 \mathrm{~J}+6.7 \mathrm{~J}=8,8 \mathrm{~J}
\end{gathered}
$$

To see the influence of a position deviation $\Delta \mathrm{x}$ from the set value $\mathrm{x}_{\text {feed }}$, experiments with $\mathrm{v}_{\text {feed }}=60 \mathrm{~mm} / \mathrm{s}$ are performed where an offset in a range of $+/-100 \mu \mathrm{m}$ is added to the feed distance $\mathrm{x}_{\text {feed }}$ and the produced linked parts probes are measured. In this case, twenty-two parts for each parameter set are measured. For the measurements a Dalsa Genie TS-1920M area-scan camera is used together with a telecentric camera lens (magnification: 3x). The effective resolution is $\operatorname{res}_{\mathrm{x}}=3.67 \mu \mathrm{m} / \mathrm{pixel}$ in $\mathrm{x}$-direction and $\mathrm{res}_{\mathrm{y}}=1.83 \mu \mathrm{m} / \mathrm{pixel}$ in $\mathrm{y}$-direction, see Fig. 6 . The probes are clamped in the probe holder with a preload force of $\mathrm{F}_{\mathrm{pl}} \approx 15 \mathrm{~N}$. As for the performed experiments no significant difference between the measurement of the two perspectives $\left(0^{\circ}\right.$ and rotated by $\left.90^{\circ}\right)$ could be noticed, in the illustrated diagrams, the average values of both measurements is used to illustrate the results.

Finally, the modified process scheme with the parallelization of preheating and transport according to Fig. 4 is tested. Parameters for a stable process are determined. These are in this case especially the correct time for closing gripper 2 and switching on the laser. The evaluation is based on the position curve and by measuring twenty-two produced parts.

\section{Results and discussion}

\subsection{Trajectory deviation / positioning behaviour}

In Fig. 8 for reasons of clear visibility only three exemplary velocity measurements of the totally seven investigated feed velocities are illustrated. The not illustrated measurements show an analog behavior. The aspired trapezoidal velocity profile with short acceleration and deceleration phases is generally achieved, but a decaying oscillation around the target value of the feed velocity $v_{\text {feed }}$ appears. The amplitude of the oscillation increases with increasing $\mathrm{v}_{\text {feed }}$. Thereby, for higher feed velocities, the aspired value is strongly exceeded and the oscillation does not end before reaching the target position. Finally, the velocity becomes negative for a short time, which indicates an overshoot, the axis overruns the target position and moves back. Aside from the oscillation, the average velocity and thereby the average fed volume per time increment is constant.

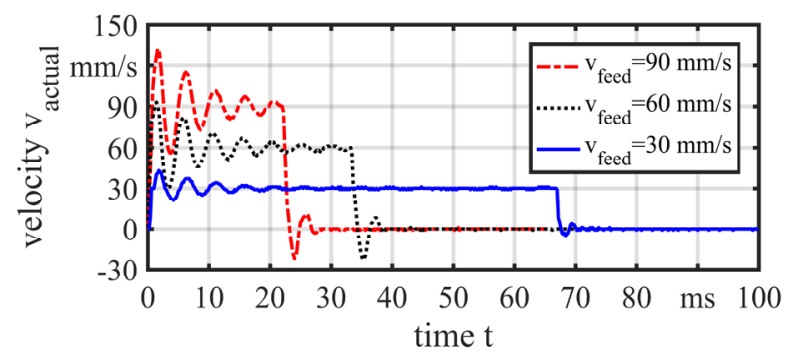

Fig. 8 Actual velocity in dependency of vfeed

For a more detailed analysis, the position measurements are considered in the following. Fig. 9 illustrates a curve of the set input position $\mathrm{x}_{\text {input }}$ and the measured actual position $\mathrm{x}_{\mathrm{act}}$ for $\mathrm{v}_{\text {feed }}=60 \mathrm{~mm} / \mathrm{s}$ as well as the according position deviation in the diagram beneath.

$$
\Delta \mathrm{x}=\mathrm{X}_{\text {input }}-\mathrm{X}_{\text {act }}
$$

The highest deviations from the input curve given to the controller appear especially in the first section and when the final position is reached. A controller needs some deviation to build up a force. This happens, when the feed starts. In consequence of the fast increasing input velocity, the deviation increases fast and an oscillation results, as already observed in the velocity curve. The oscillation decays and the mean deviation does not significantly change until the final position is reached at $\mathrm{t} \approx 34 \mathrm{~ms}$. In the end of the positioning an overshoot $\Delta \mathrm{x}_{\mathrm{o}}$ is observed, the target position is run over before the position decreases again and the deviation goes back to zero. The positioning behavior is strongly influenced by the control parameters, which in this case are optimized under the two aspects of a fast reaching of the target position and a high stiffness against disturbing forces. Hence, the oscillation was not in focus, when setting up the controller. A further possible explanation for the strong oscillation is the cycle time of the controller, which is $0.2 \mathrm{~ms}$ for the position controller and $0.1 \mathrm{~ms}$ for the velocity controller. This is close to the acceleration time, which is smaller or equal $t_{a c c, \max }=0.9 \mathrm{~ms}$ depending on the velocity. Consequently, the input value of the velocity controller is almost a step function. 

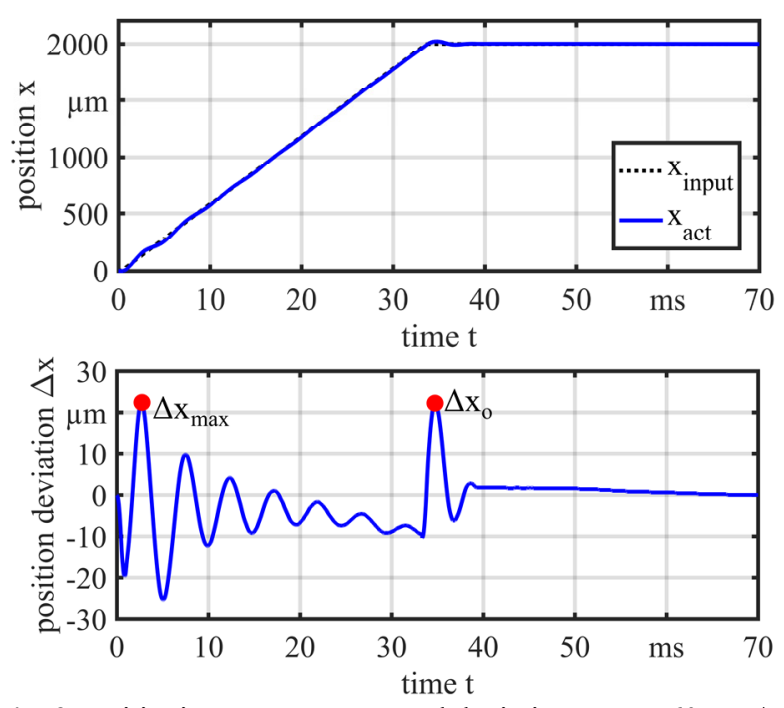

Fig. 9 Positioning measurement and deviation, vfeed $=60 \mathrm{~mm} / \mathrm{s}$

Apart from the oscillation, the maximum deviation $\Delta \mathrm{x}_{\max }$ of the position of gripper 1, which appears at the beginning of the feed, and the overshoot $\Delta x_{0}$ when reaching the target position are considered as critical values. They are illustrated in Fig. 10. The maximum deviation $\Delta \mathrm{x}_{\max }$ increases with $\mathrm{v}_{\text {feed }}$ and reaches a mean value of more than $30 \mu \mathrm{m}$ for the maximum tested velocities $v_{\text {feed }}=80 \mathrm{~mm} / \mathrm{s}$ and $v_{\text {feed }}=90 \mathrm{~mm} / \mathrm{s}$. However, the overshoot $\Delta \mathrm{x}_{0}$ only increases until $\mathrm{v}_{\text {feed }}=60 \mathrm{~mm} / \mathrm{s}$, where it reaches a maximum of $22 \mu \mathrm{m}$. Then decreases slowly and stays on a relative constant level of about $15 \mu \mathrm{m}$ up to $\mathrm{v}_{\text {feed }}=90 \mathrm{~mm} / \mathrm{s}$.

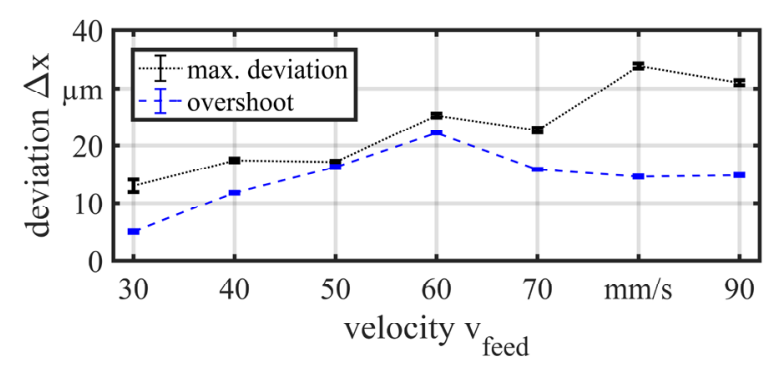

Fig. 10. Max. deviation and overshoot in dependency of $\mathrm{v}_{\text {feed }}$

The maximum position deviation $\Delta \mathrm{x}_{\max }$ directly influences the melting, where $\Delta \mathrm{x}_{\mathrm{o}}$ may have an effect on the solidification. In the current setup, the laser is switched off after the theoretical ideal positioning time independently from the actual position. Thereby, the overshoot and the moving back happens during the solidification. Taking this into account an analysis of the exact times is done on basis of three characteristic values, which are illustrated in the exemplary curve in Fig. 11. $t_{\text {pos }}$ indicates the time when the final value is reached the first time. $\mathrm{t}_{5.0}$ indicates the time after the overshoot at which the deviation from the target position stays below $\Delta \mathrm{x}=5 \mu \mathrm{m} . \mathrm{t}_{0.2}$ indicates the time after which the deviation from the target position stays below $\Delta \mathrm{x}=0.2 \mu \mathrm{m}$, which is equal to the position sensor resolution. The difference between $t_{\text {pos }}$ and $t_{\text {feed }}$, after which the laser is switched off, is below $1 \mathrm{~ms}$. It decreases with increasing feed velocity $\mathrm{v}_{\text {feed, }}$, which is not illustrated here.

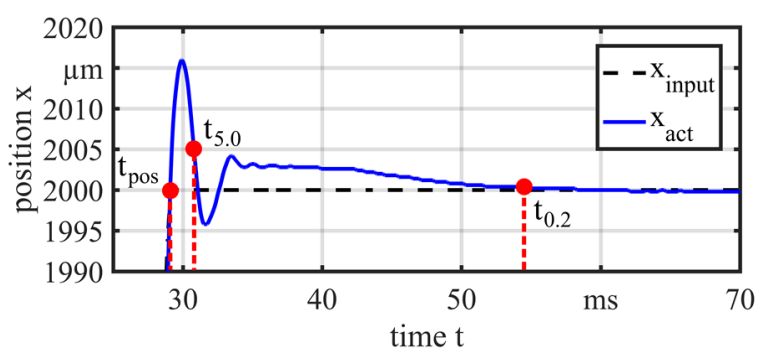

Fig. 11 Positioning measurement, vfeed $=60 \mathrm{~mm} / \mathrm{s}$

Regarding the process, what happens after switching off the laser is more important. For that reason, the following time differences are considered.

$$
\begin{aligned}
& \Delta \mathrm{t}_{5.0}=\mathrm{t}_{5.0}-\mathrm{t}_{\mathrm{pos}} \\
& \Delta \mathrm{t}_{0.2}=\mathrm{t}_{0.2}-\mathrm{t}_{\mathrm{pos}}
\end{aligned}
$$

The results are illustrated in Fig. 12. $\Delta \mathrm{t}_{5.0}$ is increasing with increasing feed velocities, from $0.3 \mathrm{~ms}$ at $\mathrm{v}_{\text {feed }}=30 \mathrm{~mm} / \mathrm{s}$ to $5.3 \mathrm{~ms}$ at $\mathrm{v}_{\text {feed }}=90 \mathrm{~mm} / \mathrm{s} . \Delta \mathrm{t}_{0.2}$ however firstly increases and reaches a maximum of $37.8 \mathrm{~ms}$ for $\mathrm{v}_{\text {feed }}=40 \mathrm{~mm} / \mathrm{s}$. Afterwards, it decreases and reaches a value of $23.7 \mathrm{~ms}$ for $\mathrm{v}_{\text {feed }}=90 \mathrm{~mm} / \mathrm{s}$.

The maximum value of $\Delta \mathrm{t}_{0.2}$ is smaller than the solidification time, which in Table 1 is specified to $130 \mathrm{~ms}$. Consequently, there is still a motion during the solidification, which may influence the part geometry. $\Delta \mathrm{t}_{5.0}$ is more significant. The maximum time $\Delta \mathrm{t}_{5.0}$ of $5.3 \mathrm{~ms}$, within the deviation falls below $5 \mu \mathrm{m}$, is relative small compared to the solidification time. Nevertheless, after that there still is a deviation in the range of $5 \mu \mathrm{m}$.

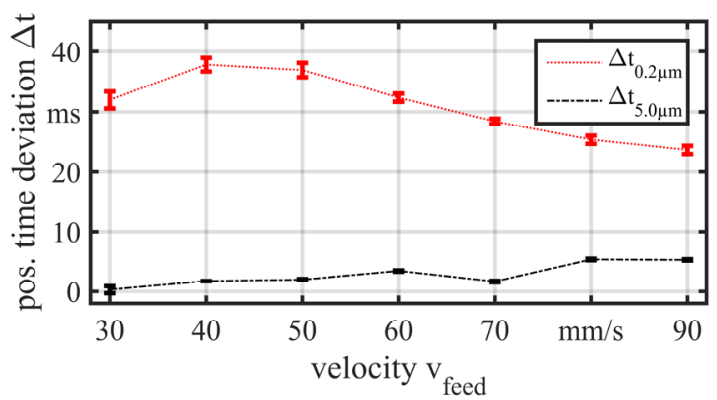

Fig. 12. Positioning time in dependency of $v_{\text {feed }}$

Finally, the laser rod melting has been tested for all given velocities and preforms could be produced without appearing of process failures up to $\mathrm{v}_{\text {feed }}=90 \mathrm{~mm} / \mathrm{s}$. Nevertheless, the oscillation could cause problems in case that $\mathrm{V}_{\text {feed }}$ is further increased. Thus, induced vibrations can have an effect on the geometry.

In Table 5 the sum of preheat time $t_{\text {preheat }}$ and melting time $t_{\text {melt }}$ is compared between the previous and the actual state. The first row shows the reached result from the previous work [14], which is summarized in Table 1. The second row shows the value reached during the currently presented experiments. As the feed $\mathrm{x}_{\text {feed }}$ was increased, for reasons of comparability to further investigations in the third row the current result is converted to the feed from the former experiments. This is done by keeping the preheat time $t_{\text {preheat}}$, which is independent of the feed and calculating the feed time $t_{\text {feed }}$ 
for $\mathrm{x}_{\text {feed }}=1.7 \mathrm{~mm}$. In this case, a cycle time reduction of $15 \mathrm{~ms}$ respectively $5 \%$ is achieved.

Table 5. Transport time in detail

\begin{tabular}{|l|c|c|c|}
\hline source & $\mathbf{v}_{\text {feed }}$ & $\mathbf{x}_{\text {feed }}$ & $\mathbf{t}_{\text {preheat }}+\mathbf{t}_{\text {melt }}$ \\
\hline$[14]$ & $50 \mathrm{~mm} / \mathrm{s}$ & $1.7 \mathrm{~mm}$ & $7 \mathrm{~ms}+34 \mathrm{~ms}=41 \mathrm{~ms}$ \\
\hline actual work & $90 \mathrm{~mm} / \mathrm{s}$ & $2.0 \mathrm{~mm}$ & $7 \mathrm{~ms}+22 \mathrm{~ms}=29 \mathrm{~ms}$ \\
\hline $\begin{array}{l}\text { act. work } \\
\text { converted }\end{array}$ & $90 \mathrm{~mm} / \mathrm{s}$ & $1.7 \mathrm{~mm}$ & $7 \mathrm{~ms}+19 \mathrm{~ms}=26 \mathrm{~ms}$ \\
\hline
\end{tabular}

\subsection{Influence of position deviations on the parts}

In the previous section, positioning deviations in context of feed velocity have been discussed. With respect to the final geometry especially the solidification and thereby the final positon is expected to be important. To analyze the influence of a position deviation $\Delta \mathrm{x}_{\text {feed }}$ from the set feed $x_{\text {feed }}$ the net part volume $V_{\text {part,net }}$ (see Fig. 13) is considered based on experiments with $\mathrm{V}_{\text {feed }}=60 \mathrm{~mm} / \mathrm{s}$. The data shows that in a range of $\Delta \mathrm{x}_{\text {feed }}=+/-20 \mu \mathrm{m}$ the preforms change only slightly. It can be stated that for $\Delta \mathrm{x}_{\text {feed }}=0$ the net part volume is equal to the volume of the wire fed during the melting $\mathrm{V}_{\text {wire,feed }}=0.20 \mathrm{~mm}^{3}$. Thereby, the material must have been molten properly despite the oscillations observed from the measurements in the previous section. In the mentioned range of $\Delta \mathrm{x}_{\text {feed }}=+/-20 \mu \mathrm{m}$ the net part volume deviation stays within $\Delta \mathrm{V}_{\text {part,net }} \approx+/-1 \%$. A negative $\Delta \mathrm{x}_{\text {feed }}$ clearly reduces the part volume. Considering the maximum negative position deviation $\Delta \mathrm{x}_{\text {feed }}=-100 \mu \mathrm{m}, \quad \mathrm{a}$ theoretical volume deviation of $\Delta \mathrm{V}_{\text {theo }}=0.01 \mathrm{~mm}^{3}$ results.

$$
\Delta \mathrm{V}_{\text {theo }}=\left(\mathrm{d}_{\text {wire }} / 2\right)^{2} \cdot \pi \cdot \Delta \mathrm{x}_{\text {feed }}=0.01 \mathrm{~mm}^{3}
$$

This is a theoretical deviation of $5 \%$ and again conforms to the measurement in the diagram. In contrast, a positive position deviation does not change the volume significantly. A saturation, where no further material is molten appears, is also described in [14].

Relating these results to the results from the previous section, it can be stated that the deviations that appear in consequence of an increased feed velocity do not have a significant effect on the geometry of the preforms. The process seems to be quite robust against small position deviation in the range of $\Delta \mathrm{x}_{\text {feed }}=+/-20 \mu \mathrm{m}$. Especially the overshoot seems to be uncritical.

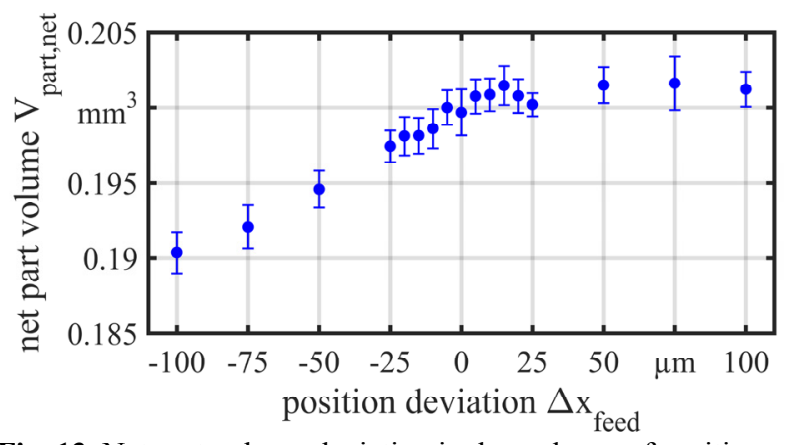

Fig. 13. Net part volume deviation in dependency of position deviation, $v_{\text {feed }}=60 \mathrm{~mm} / \mathrm{s}$

\subsection{Parallelized process}

The objective of the investigations in this section is a further cycle time reduction by parallelization. Concretely, the time for closing gripper $2(17 \mathrm{~ms})$ can be saved. The effect of the parallelization on the feed is considered and probes are produced. Fig. 14 illustrates an exemplary position curve for the parallelized process. In contrast to Fig. 3 it begins with the return stroke (4) and then continues with the parallelized forward stroke (5) and preheat (1) as mentioned in section 2. The transport distance is $x_{\text {transport }}=10 \mathrm{~mm}$ and the feed distance is again $x_{\text {feed }}=2 \mathrm{~mm}$. The return stroke is the sum of both values $\mathrm{x}_{\text {return }}=\mathrm{x}_{\text {transport }}+\mathrm{x}_{\text {feed }}=12 \mathrm{~mm}$. The interesting zone in the curve is the direct transition between transport and feed at $\mathrm{t} \approx 81 \mathrm{~ms}$ and $\mathrm{x}=0 \mathrm{~mm}$, which saves the time for closing gripper 2 .

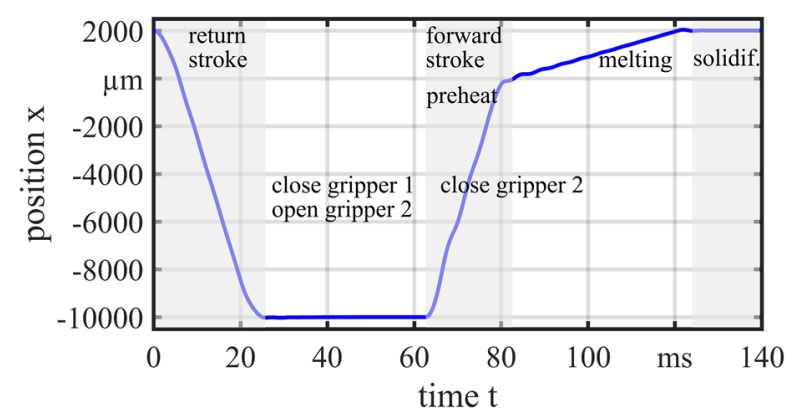

Fig. 14 Parallelized process - position curve, vfeed $=50 \mathrm{~mm} / \mathrm{s}$ and Vtransport $=600 \mathrm{~mm} / \mathrm{s}$

The solidification time and the time for opening gripper 1 are not illustrated completely in the curve, because the feed axis stands still during this time. Values are given in Table 1 and Table 2. Fig. 15 shows the correspondent velocity curve. The feed velocity is $V_{\text {feed }}=50 \mathrm{~mm} / \mathrm{s}$ in this case. The curve corresponds to the curves in Fig. 8 where the sequential process is considered.The same oscillations appear and for the return stroke as well as the transport they are even stronger, which has no significant influence on the feed during the melting. Nevertheless, a stable process could be realized. Table 3 compares the measured parts for the sequential (section 4.3) and the parallelized process. As the coordination of the parallelized process is much more difficult, it is more complex to adapt the part geometry. The differences for the measured characteristic values can mainly be explained by a different feed $\mathrm{x}_{\text {feed, }}$ which can be recognized by the different net part volume. Nevertheless, the standard deviation is on a similar level for both process variants. A significant difference can only be seen in the part length. However, as explained before, the determination of the part length from the measurements is more complicated, which might be a reason for the difference here. This leads to the assumption, that the new process layout can be applied to reduce cycle time further by $24 \mathrm{~ms}$ respectively $8.8 \%$ compared to Table 1 (the sum of preheat time and the time for closing gripper 2). A comparison of the standard deviations shows, that the reproducibility does not suffer by this measure. The deviation in the part geometry is explained by a difference in the effective feed $\mathrm{x}_{\text {feed }}$, 
which for the new approach depends on the time when closing gripper 2.

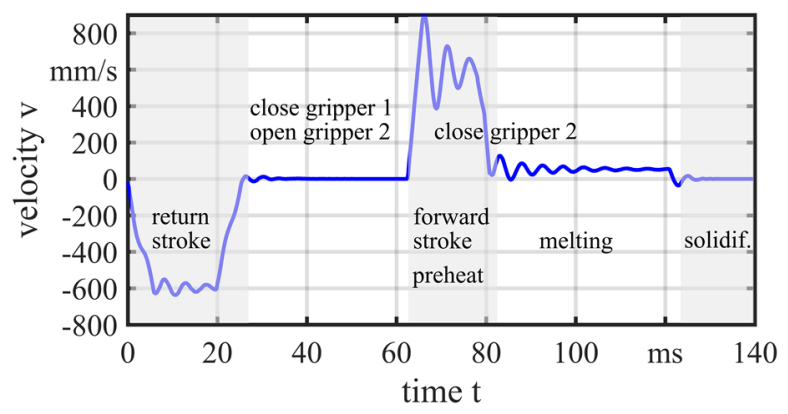

Fig. 15 Parallelized process - velocity curve

Table 3. Comparison sequential and parallelized process

\begin{tabular}{|l|c|c|}
\hline & $\begin{array}{c}\text { Sequential } \\
\text { process }\end{array}$ & $\begin{array}{c}\text { Parallelized } \\
\text { process }\end{array}$ \\
\hline$V_{\text {feed }}[\mathrm{mm} / \mathrm{s}]$ & 60 & 50 \\
\hline $\mathrm{L}_{\text {part }}[\mu \mathrm{m}]$ & $1135+/-32$ & $1281+/-37$ \\
\hline$d_{\text {part }}[\mu \mathrm{m}]$ & $743+/-5$ & $702+/-5$ \\
\hline$G$ & $0.66+/-0.02$ & $0.55+/-0.02$ \\
\hline$V_{\text {part }}\left[\mathrm{mm}^{3}\right]$ & $0.317+/-0.004$ & $0.312+/-0.005$ \\
\hline$V_{\text {part,net }}\left[\mathrm{mm}^{3}\right]$ & $0.20+/-0.001$ & $0.181+/-0.002$ \\
\hline
\end{tabular}

\section{Conclusion and outlook}

The behavior of the feed unit has been investigated in a velocity range between $v_{\text {feed }}=30 \mathrm{~mm} / \mathrm{s}$ and $\mathrm{v}_{\text {feed }}=90 \mathrm{~mm} / \mathrm{s}$. The applied control parameters were optimized under the two aspects of a fast reaching of the target position and a high stiffness against disturbing forces. Under these conditions a significant oscillation of the actual feed velocity $\mathrm{v}_{\text {feed }}$ could be observed, which resulted in a maximum position deviation $\Delta \mathrm{x}_{\max }$ of more than $30 \mu \mathrm{m}$ for the maximum tested velocities $\mathrm{v}_{\text {feed }}=80 \mathrm{~mm} / \mathrm{s}$ and $\mathrm{v}_{\text {feed }}=90 \mathrm{~mm} / \mathrm{s}$. The maximum measured overshoot was $\Delta \mathrm{x}_{\mathrm{o}}=22 \mu \mathrm{m}$. Nevertheless, linked parts could be produced for all tested velocities without appearing of process failures. Regarding the influence of a position deviation, it was found, that in a range of $\Delta \mathrm{x}_{\text {feed }}=+/-20 \mu \mathrm{m}$ the net part volume deviation stays within $\Delta \mathrm{V}_{\text {part,net }} \approx+/-1 \%$. Especially a positive deviation seems to be uncritical, due to the appearing of a saturation. Thereby, the deviation in consequence of the overshoot, which falls below $5 \mu \mathrm{m}$ in less than $5.3 \mathrm{~ms}$ is assumed to be uncritical. Finally, a new parallelized process approach could be tested successfully, which allows a further cycle time reduction without worsening the reproducibility of the geometry of the produced parts. By combining all the described measures and under the assumption of a feed of $\mathrm{x}_{\text {feed }}=1.7 \mathrm{~mm}$, the cycle time could be reduced by $39 \mathrm{~ms}$ respectively $14.4 \%$ compared to [14]. Like this, cycle times are below $t_{\text {cylce }}<232 \mathrm{~ms}$ respectively output rates of more than 258 parts/minute can be reached. The process resulted to be quite robust against the appearing oscillations and the resulting deviations. Nevertheless, for the tested velocities the feed unit is operated at its limits and process failures could appear, when further increasing the feed velocity. Measures that could be tested for reducing those oscillations are mainly seen in the controller. This could be a controller with shorter cycle times or an adaptive control.

The authors gratefully acknowledge the financial support by Deutsche Forschungsgemeinschaft (DFG, German Research Foundation) for the subprojects C5 "Linked Parts" and A3 "Material Accumulation" within the SFB 747 (Collaborative Research Center) "Micro Cold Forming-Processes, Characterization, Optimization".

\section{References}

1. L. Alting, F. Kimura, H.N. Hansen, G. Bissacco, CIRP Annals Manuf. Tech. 52, 635 (2003)

2. F. Vollertsen, D. Biermann, H.N. Hansen, I. S. Jawahir, K. Kuzman, CIRP Annals Manuf. Tech. 58, 566 (2009)

3. H. van Brussel, J. Peirs, D. Reynaerts, A. Delchambre, G. Reinhart, N. Roth, M. Weck, E. Zussman, CIRP Annals Manuf. Tech. 49, 451 (2000)

4. G. Fantoni, M. Porta, IFIP Micro Assembly Technologies and Applications, 223 (Springer, New York, Berlin, Heidelberg, 2008)

5. M. Tichem, D. Lang, B. Karpuschewski, Ass. Aut. 24, 88 (2004)

6. M. Arentoft, R.S. Eriksen, H.N. Hansen, N.A. Paldan, CIRP Annals Manuf. Tech. 60, 335 (2011)

7. B. Kuhfuss, E. Moumi, K. Tracht, F. Weikert, F. Vollertsen, A. Stephen, Proceedings of $14^{\text {th }}$ international ESAFORM conference on material forming, (AIP, 2011)

8. M. Merklein, T. Stellin, U. Engel, Key Eng. Mat. 504-506, 587 (2012)

9. F. Vollertsen, R. Walther, CIRP Annals Manuf. Tech. 57, 291 (2008)

10. C. Schattmann, C. Hennick, H. Bruening, F. Pfefferkorn, F. Vollertsen, Journal for Technology of Plasticity 42(1), (2017)

11. P. Wilhelmi, C. Schenck, B. Kuhfuss, Journal of Mech. Eng. and Autom. 7, 44-49, (2017)

12. H.Lin, C. Lee, Y. Lin, C.-H. Li, Key Engineering Materials, 623, 725 (2014)

13. P. Wilhelmi, E. Moumi, C. Schenck, B. Kuhfuss, Proceedings of 5. Kolloquium Mikroproduktion (german), (2015)

14. C. Schattmann, P. Wilhelmi, C. Schenck, B. Kuhfuss, F. Vollertsen, Proceedings of 8. Kolloquium Mikroproduktion (german), (2017) 